\title{
A Competitive Model of (Super)Stars
}

\author{
by
}

Timothy Perri*

Revised March 17, 2005

*Professor of Economics, Appalachian State University, Boone, NC, 28608. E-mail:

perritj@appstate.edu. I thank Kyung Baik, David Dickinson, Peter Frykblom, Pete Groothuis, Fred

Wallace, and seminar participants in the Department of Economics at Appalachian State University for comments on an earlier version of this paper.

JEL classification: D21 and D41

Key words: superstars and competition 


\begin{abstract}
The usual explanations for superstar effects---when a firm's revenue is positive and convex in quality, and a few firms earn a large share of market revenue---are imperfect substitution between sellers, low marginal cost of output, and marginal cost declining as quality increases. Herein, a competitive model is developed in which superstar effects occur simply because a few firms have quality significantly higher than others. No firm needs to sell more than a small percentage of market output, and cost can increase in output and in quality (the latter possibly at no more than a decreasing rate).
\end{abstract}




\section{Introduction}

In his 1981 paper, Sherwin Rosen was the first to formally analyze the phenomenon of what he called superstars. ${ }^{1}$ Rosen assumed more talented individuals produce higher quality products. Assuming, for simplicity of discussion, individual talent and product quality are identical, superstar effects imply earnings are convex in quality, the highest quality producers earn a disproportionately large share of market earnings, and the possibility of only a few sellers in the market. Rosen argued superstar effects were the result of two phenomena: 1) imperfect substitution among products, with demand for higher quality increasing more than proportionally, so small differences in talent may result in large earnings differences, ${ }^{2}$ and 2) technology such that one or a few sellers could profitably satisfy market demand, with higher quality producers having lower marginal cost of output. ${ }^{3}$ In the extreme case, we have a joint good, where an additional buyer can be serviced at little additional cost to the seller. Borghans and Groot (1998) refer to a market with such cost conditions as one with “media stars.” Rosen (1983) argues such markets almost always require mass media, and, depending on the distribution of consumer preferences, may contain only a few sellers. Television shows and recorded music are examples of media markets.

However, imperfect substitution and joint consumption do not characterize all markets in which superstar effects appear. ${ }^{4}$ For example, in a paper discussed below, Krueger (2005) identifies significant superstar effects for music concerts ${ }^{5}$---effects that have become even larger in recent years. ${ }^{6}$ He argues the time and effort to perform a song should not have changed much in over time. It is also unlikely the cost of performing a song depends significantly on the quality of the musicians. Further, the technology of reaching more buyers for a live performance is much different than it is for selling additional CDs. As

\footnotetext{
1 Not surprisingly, Adam Smith considered what he called the “exorbitant rewards” of some (Smith, 1976/1982, p. 209). See the discussion in Borghans and Groot (1998).

2 In Adler's (1985) model, superstar effects develop when consumption requires knowledge, as in music appreciation, and do not require any talent differences.

${ }^{3}$ If marginal cost of output is very low, and rises little with output, higher quality can not lower cost too much. In the paper herein, marginal cost is assumed to increase non-trivially as output increases, and higher quality need not lower marginal cost in order to obtain superstar effects.

4 Frank and Cook (1992) refer to "winner-take-all markets" which are essentially the same as markets with superstar effects. Their results will be discussed below.

5 Hamlen (1991) notes the term "superstar" is repeatedly used in reference to the field of popular music.

${ }^{6}$ Sorensen (2004) finds growing superstar effects in the market for best-selling books. From the mid-1980s to the mid-1990s, the share of books sold by the top thirty authors nearly doubled. By 1994, 70\% of all fiction sales were accounted for by four authors: Clancy, Crichton, Grisham, and King.
} 
Rosen noted: "It is preferable to hear concerts in a hall of moderate size rather than in Yankee Stadium."7 Quality of live performances is significantly diluted by audience size (Rosen, 1983), and cost thus increases in market size. ${ }^{8}$

In order to consider superstar effects in the absence of imperfect substitution and joint consumption, in this paper, a competitive model is developed in which: i) there are many firms, most of which have the lowest quality level, and none of which sells a significant share of market output; ii) a fraction of potential low quality sellers could satisfy market demand; iii) complete arbitrage occurs between prices of goods with different quality; iv) a few firms with higher quality have revenue that increases with quality at an increasing rate; and v) high quality sellers earn a disproportionately large share of market revenue, provided their quality is significantly higher than that of low quality sellers. Assumption iii implies quality levels are perfect substitutes. That is, if $\mathrm{z}=$ product quality, seller "i” has $\mathrm{z}=\mathrm{z}_{\mathrm{i}}$, and seller “ $\mathrm{j}$ ” has $\mathrm{z}=\mathrm{z}_{\mathrm{j}}, \mathrm{z}_{\mathrm{i}} \neq \mathrm{z}_{\mathrm{j}}$, then arbitrage will result in prices such that $\mathrm{P}\left(\mathrm{z}_{\mathrm{i}}\right)=\frac{\mathrm{z}_{\mathrm{i}}}{\mathrm{z}_{\mathrm{j}}} \mathrm{P}\left(\mathrm{z}_{\mathrm{j}}\right)$.

Since some firms could have quality only slightly greater than that of the lowest level of quality, it seems a bit extreme to refer to such firms as superstars. Thus, all firms with quality above the lowest level will be referred to as stars. Since the concept of superstar effects is well established, superstar will still be used to denote the phenomena of revenue increasing and convex in quality, and a few sellers earning a large percentage of market revenue. Rosen (1981) used profit when considering superstar effects, but revenue is used herein. Profit is not used for the following reasons. First, in the competitive model herein, low quality producers earn zero profit. Thus, stars always earn all market profit. Second, in the special case in Rosen that is closest to the model herein (1981, pp. 851-’52), revenue and profit are identically affected by quality, as is true in our competitive model. Third, earnings reported for top performers in entertainment are not net of cost. The data on concert earnings from Krueger (2005) considered below involve revenue.

\footnotetext{
${ }^{7}$ Rosen, 1981, P. 849.

${ }^{8}$ Cost increases in market size because it is more expensive to reach a larger audience in a given concert, but, more importantly, the large decline in quality as the audience at a concert grows necessitates more concerts to reach additional customers.
} 
In order for a star seller to earn a disproportionately large share of market revenue, it must have quality significantly greater than that of low-quality sellers, non-stars. In Rosen’s model (1981), superstars are not required to have significantly higher quality than other sellers in order for the former to have revenue convex in quality, and a few firms (superstars) earning a large percentage of market revenue. However, as noted above, Rosen’s superstar results require imperfect substitution or joint consumption, neither of which is required herein.

Rosen (1981) briefly considered a case similar to that herein in which technology is such a few producers could not profitably sell a large percentage of market output; he found superstar effects in that case. However, Rosen spent little time on that situation, focused mainly on the case with joint consumption, and left many questions unanswered that will be addressed herein.

First, what cost conditions allow for superstar effects? Must cost be negatively related to, or at least independent of quality? Second, do stars represent a significant percentage of all sellers, as Rosen implied, and is suggested in the models in MacDonald (1988) and Borghans and Groot (1998)? ${ }^{9}$ Third, in Rosen's superstar model, price depends on a seller's output. The threat of entry and the assumption sellers of similar quality are good substitutes force firms to behave competitively. However, the extent of substitution is assumed to diminish for goods farther apart in quality. If stars are very scarce, potential entrants are likely to be of the lowest quality---otherwise they would already be in the market. ${ }^{10}$ Thus entry of stars is problematic. Combined with the possibility stars may differ significantly in quality, there may be little reason to suspect competitive behavior in such a market. In the model herein, there are many sellers, and free entry and exit exist for sellers with the lowest quality. Fourth, Rosen compared the analysis in the special case in his 1981 paper to the model in his paper on hedonic prices (Rosen, 1974). In his earlier paper, Rosen assumed arbitrage was not possible. In the case of hedonic prices, a good may have many attributes, one bundle of attributes may not be comparable to another, and thus it seems

\footnotetext{
9 MacDonald (1988) models “rising stars” who obtain good initial reviews and ultimately serve a vast audience.

10 The idea is buyer preferences determine who is a star. Thus, for example, a band whose members can sing and play instruments as well as the Rolling Stones will not have a level of z comparable to that of the Stones. A new music group that enters the market may, at some point, be viewed as high quality, given whatever occurs for consumers to judge them that way. However, producers can not simply create a high level of $\mathrm{z}$, which is why entry of stars is problematic.
} 
reasonable to assume arbitrage does not occur. However, in Rosen's superstar model (as in the model herein), quality is one-dimensional, with all consumers valuing quality identically. In this case, there seems no reason why arbitrage between different quality levels should not occur. With free entry, a large number of potential producers with low quality, and full arbitrage between quality levels, a competitive market results without Rosen's assumptions of potential entry by (super)stars and sellers having similar quality levels. ${ }^{11}$

One question not addressed herein is why some are viewed as higher quality than others. ${ }^{12}$ Becker and Murphy (2000) offer one reason for the existence of stars in what they call social markets. They argue some (followers) gain acceptance and prestige by emulating the consumption of others (leaders). Whatever the reason for the existence of stars, technological advances in recent years may have caused the perceived quality of stars in some sectors to increase. Products such as Walkman, Discman, and iPod enable consumers to listen to music virtually anywhere. If the music market is indeed "social," the ability of followers to emulate leaders would have increased, implying an increase in consumers' valuation of higher quality products.

The outline of the rest of the paper is as follows. In Section 2, we consider how cost and quality must be related in order to have superstar effects. In Section 3, there is a relatively informal analysis of market equilibrium. A more formal analysis of a market with superstar effects is presented in Section 4. Section 5 contains a discussion of recent changes in the market for music concerts. Concluding remarks are presented in Section 6.

\section{Cost and superstar effects}

\footnotetext{
${ }^{11}$ Becker and Murphy (2000) note competition and free entry yield a price equal to the marginal and average cost of new units, implying superstar effects can not result in such a world. However, higher quality sellers can sell at higher prices and earn positive economic profit if free entry is at the lowest quality level.

12 One could argue the model herein is simply one of product differentiation. The standard monopolistic competition model (Varian, 2003) assumes each firm has a downward-sloping demand, with a firm's elasticity of demand increasing (in absolute value) the more firms that are active. Herein, it is assumed there are many producers, which alone implies highly elastic firm demand, and different products are perfect substitutes, yielding perfectly elastic firm demand.
} 
In this section, we consider the cost conditions necessary for superstar effects to occur. Rosen (1981) essentially defined superstar effects as the situation in which what he called net revenue (i.e. profit) is convex in talent, and a few sellers earn a disproportionate share of market net revenue. Herein, talent is labeled as quality, denoted by $\mathrm{z}$, and, for reasons given in the previous section, the main focus is on revenue, R, and not profit. In Rosen's general model, product quality is positively related to seller talent or quality, and negatively related to the number of units produced.

Suppose product and seller quality are identical, ${ }^{13}$ and the effect of quality on cost can be positive, zero, or negative. Total cost for a firm, C, is given by:

$$
\mathrm{C}=\mathrm{z}^{\sigma} \mathrm{q}^{\alpha}+\mathrm{F}
$$

where $\alpha>1, \mathrm{q}=$ the firm's output, and F = fixed cost. Rosen (1981) argued superstar effects occur in a market when "...fewer are needed to serve it the more capable they are."14 This essentially means marginal cost is inversely related to quality, or given eq.(1), $\sigma<0$. To see what is necessary for superstar effects, let product price, $\mathrm{P}$, be linear in $\mathrm{z}$ : $\mathrm{P}=\mathrm{kz}$, where $\mathrm{k}$ is a positive number, independent of $\mathrm{z}$, with a value that will be determined in the next section. The firm is a price taker: $\mathrm{P}$ is independent of firm output, q. Thus profit, $\pi$, is given by:

$$
\pi=\mathrm{kzq}-\mathrm{z}^{\sigma} \mathrm{q}^{\alpha}-\mathrm{F}
$$

Proposition One. Given the assumed cost function, revenue is increasing and convex in quality even if total cost increases in product quality as long as it does so at a decreasing rate.

Proof. Find the profit-maximizing choice of q, substitute the result into R and $\pi$, and differentiate $\mathrm{q}, \mathrm{R}$, and $\pi$ with respect to $\mathrm{z} .{ }^{15}$ Let the profit-maximizing values of $\mathrm{q}, \mathrm{R}$, and $\pi$ be denoted by $\mathrm{q}^{*}, \mathrm{R}^{*}$, and $\pi^{*}$, respectively.

$$
\frac{\partial \pi}{\partial q}=k z-\alpha z^{\sigma} q^{\alpha-1}=0,
$$

\footnotetext{
13 As a special case, Rosen (1981 pp. 851-‘52) considered the situation with product quality identical to seller quality.

14 Rosen, 1981, p. 847.

15 Even though the focus herein is on revenue, we also illustrate the effect of quality on profit.
} 


$$
\begin{aligned}
& \mathrm{q}^{*}=\left(\frac{\mathrm{k}}{\alpha}\right)^{\frac{1}{\alpha-1}} \mathrm{z}^{\frac{1-\sigma}{\alpha-1}}, \\
& \mathrm{R}^{*}=\left(\frac{1}{\alpha}\right)^{\frac{1}{\alpha-1}} \mathrm{k}^{\frac{\alpha}{\alpha-1} \mathrm{z}^{\frac{\alpha-\sigma}{\alpha-1}},} \\
& \pi^{*}=(\alpha-1)\left(\frac{\mathrm{k}}{\alpha}\right)^{\frac{\alpha}{\alpha-1}} \mathrm{z}^{\frac{\alpha-\sigma}{\alpha-1}}-\mathrm{F}, \\
& \frac{\partial \mathrm{q} *}{\partial \mathrm{z}}=\left(\frac{\mathrm{k}}{\alpha}\right)^{\frac{1}{\alpha-1}}\left(\frac{1-\sigma}{\alpha-1}\right) \mathrm{z}^{\frac{2-\sigma-\alpha}{\alpha-1}}, \\
& \frac{\partial \mathrm{R} *}{\partial \mathrm{z}}=\left(\frac{1}{\alpha}\right)^{\frac{1}{\alpha-1}}\left(\frac{\alpha-\sigma}{\alpha-1}\right) \mathrm{k}^{\frac{\alpha}{\alpha-1}} \mathrm{z}^{\frac{1-\sigma}{\alpha-1}}, \\
& \frac{\partial^{2} \pi^{*}}{\partial \mathrm{z}^{2}}=(\alpha-1) \frac{(\alpha-\sigma)(1-\sigma)}{\partial \mathrm{z}}\left(\frac{\mathrm{k}}{\alpha}\right)^{\frac{\alpha}{\alpha-1}} \mathrm{z}^{\frac{2-\alpha-\sigma}{\alpha-1}}
\end{aligned}
$$

There are seven possible cases of interest : Case I, $\sigma>\alpha$; Case II, $\sigma=\alpha$; Case III, $1<\sigma<\alpha$; Case IV, $\sigma=1$; Case V, $0<\sigma<1$; Case VI, $\sigma=0$; and Case VII, $\sigma<0$.

Case I. With $\sigma>\alpha$ and $\alpha>1$, using eqs. (7) - (9), the profit-maximizing q decreases in $\mathrm{z}$, and this effect is larger in absolute value than the positive effect of $\mathrm{z}$ on P. Thus $\mathrm{R}^{*}$ and $\pi^{*}$ both decline as $\mathrm{z}$ increases, and, since those with $\mathrm{z}=\mathrm{z}_{0}$ earn zero profit (see Section 3), higher quality producers would not exist in this market.

Case II. With $\sigma=\alpha, \mathrm{R}^{*}$ and $\pi^{*}$ are independent of $\mathrm{z}$ (eqs.(5) and (6)). Revenue is independent of $\mathrm{z}$ since the negative effect of $\mathrm{z}$ on the profit-maximizing q exactly offsets the positive effect of $\mathrm{z}$ on P. In this 
case, since $\mathrm{C}$ is convex in $\mathrm{z}$, one might think $\pi^{*}$ must be inversely related to $\mathrm{z}$. However, the negative effect of $\mathrm{z}$ on the profit-maximizing q means producers with higher quality produce commensurately less; thus total cost and profit are independent of z. Producers with different quality levels can co-exist, but all have the same revenue and profit.

Cases III and IV. When $1<\sigma<\alpha$, the profit-maximizing $\mathrm{q}$ is still inversely related to q, but this effect is small enough both $\mathrm{R}^{*}$ and $\pi^{*}$ increase with $\mathrm{z}$, but at a decreasing rate (eqs.(8)-(11)). When $\sigma=1$, $\mathrm{q}^{*}$ is independent of $\mathrm{z}$. In this case, with $\mathrm{P}$ linear in $\mathrm{z}$, we find $\mathrm{R}^{*}, \mathrm{C}$, and $\pi^{*}$ all increase with $\mathrm{z}$ at a constant rate. In both of these cases, higher quality producers have higher $\mathrm{R}^{*}$ and $\pi^{*}$, but no superstar effect exists. Cases $V$-VII. With $\sigma<1$, the profit-maximizing $\mathrm{q}$ is now positively related to $\mathrm{z}$, and both $\mathrm{R}^{*}$ and $\pi^{*}$ are convex in $\mathrm{z}$. Thus, a superstar effect can exist if cost increases with $\mathrm{z}$ at a decreasing rate. If $\sigma=0$, cost is independent of z, and, if $\sigma<0$, C is inversely related to z. Clearly, for $\sigma<1$, the smaller is $\sigma$, the larger is $\frac{\partial^{2} R^{*}}{\partial z^{2}}$, that is, the more convex $R^{*}$ is.

It is not possible to replicate the results above using a general relation between cost and quality. However, with a simple, specific relation between cost and output, and a general relation between cost and quality, it can be demonstrated (see the Appendix) a positive but diminishing effect of quality on cost may not be necessary, and is not sufficient for revenue to be positively related to and convex in quality.

\section{Market equilibrium}

In this section, a competitive model is developed in which most sellers (non-stars) have the minimum quality level, $\mathrm{z}_{0}$, and a few sellers (stars) have higher quality. The discussion at this point will be relatively informal. A more formal analysis that illustrates the magnitude of superstar effects (i.e. a firm's revenue is convex in quality, with a few sellers earning a large percentage of market revenue) is developed in the next section. 
Unlike media markets described in Section 1, consider a market in which there are many potential sellers, no one of which produces a significant fraction of total output in the market, $\mathrm{Q}$. There are many sellers with quality $\mathrm{z}_{0}$, free entry and exit of this type of seller occurs, and, absent sellers with $\mathrm{z}>\mathrm{z}_{0}$, some fraction of the sellers with quality $z_{0}$ could satisfy market demand, with each firm earning zero profit. For simplicity, assume cost is independent of quality, which as shown in the previous section, is not necessary for the existence of superstar effects.

As noted earlier, the assumption herein is quality levels are perfect substitutes. Arbitrage yields relative prices; in order to determine actual price levels, suppose each firm has a typical U-shaped average cost curve that is independent of quality. Now entry or exit of non-stars will force the long-run price of the lowest quality level, $\mathrm{z}_{0}$, to equal the height of the minimum point of average cost, $\mathrm{P}_{0}$. For any arbitrary quality z:

$$
\mathrm{P}(\mathrm{z})=\frac{\mathrm{z}}{\mathrm{z}_{0}} \mathrm{P}_{0}
$$

Note the constant term $\mathrm{k}$ introduced in the previous section is $\mathrm{k} \equiv \frac{\mathrm{P}_{0}}{\mathrm{z}_{0}}$. Market demand will depend on the average quality sold, $\bar{Z}$, with inverse market demand equal to $P^{D}=f(Q, \bar{Z})$, where $P^{D}$ indicates the demand price for the average quality in the market.

Proposition Two. If $\mathrm{P}^{\mathrm{D}} / \overline{\mathrm{Z}}$ is independent of $\overline{\mathrm{Z}}$, then long-run $Q$ is also independent of $\overline{\mathrm{Z}}$.

Proof. Suppose $\mathrm{P}^{\mathrm{D}}=\overline{\mathrm{Z}} \mathrm{g}(\mathrm{Q})$. Then, with $\mathrm{P}^{\mathrm{D}}=\mathrm{P}(\overline{\mathrm{z}})$ in long-run equilibrium, $\mathrm{P}^{\mathrm{D}} / \overline{\mathrm{z}}=\mathrm{P}(\overline{\mathrm{z}}) / \overline{\mathrm{z}}=\mathrm{g}(\mathrm{Q})$. However, using eq.(12), $\mathrm{P}(\overline{\mathrm{z}}) / \overline{\mathrm{z}}=\mathrm{P}\left(\mathrm{z}_{0}\right) / \mathrm{z}_{0}=\mathrm{P}_{0} / \mathrm{z}_{0}$. Thus $\mathrm{Q}=\mathrm{g}^{-1}\left(\mathrm{P}_{0} / \mathrm{z}_{0}\right)$, which is independent of $\bar{z}$. If inverse market demand is of the form $P^{D}=\bar{z} g(Q)$, then the price consumers are willing to pay per unit of quality, $\mathrm{P}^{\mathrm{D}} / \overline{\mathrm{z}}$, is independent of average quality, and arbitrage and free entry and exit of non-stars imply the number of non-stars decreases (increases) as the number of stars increases (decreases) to keep Q unchanged in long run equilibrium as $\bar{Z}$ varies. 
Proposition Three. With inverse market demand equal to $P^{D}$, if $\frac{\partial \ln \mathrm{P}^{\mathrm{D}}}{\partial \ln \overline{\mathrm{z}}}$ exceeds some value $x, x>1$, then an influx of stars that raises $\bar{Z}$ will induce more non-stars to enter the market. Otherwise, an influx of stars will tend to cause non-stars to leave the market.

Proof. With a market demand like the one considered above--- $\mathrm{P}^{\mathrm{D}}=\overline{\mathrm{z}} \mathrm{g}(\mathrm{Q})$----we have $\frac{\partial \ln \mathrm{P}^{\mathrm{D}}}{\partial \ln \overline{\mathrm{z}}}=1$. In this case, if new stars now develop and enter the market, ${ }^{16}$ causing $\bar{z}$ to increase, demand increases vertically by the same percentage that $\bar{z}$ increased. However, the market equilibrium price for average quality, $\mathrm{P}(\overline{\mathrm{z}})$ increases by a smaller percentage because i) supply is not vertical, and ii) supply increased. Thus $\mathrm{P}(\overline{\mathrm{z}})<\frac{\overline{\mathrm{z}}}{\mathrm{z}_{0}} \mathrm{P}_{0}$. However, arbitrage requires $\mathrm{P}\left(\mathrm{z}_{0}\right)=\frac{\mathrm{z}_{0}}{\overline{\mathrm{z}}} \mathrm{P}(\overline{\mathrm{z}})$, so $\mathrm{P}\left(\mathrm{z}_{0}\right)<\mathrm{P}_{0}$, which means non-stars earn negative profit. Some non-stars will exit, ${ }^{17}$ decreasing market supply, but also raising $\overline{\mathrm{z}}$ and thus increasing market demand. Both the demand increase and supply decrease will raise $P(\bar{z})$, and this process will continue until $\mathrm{P}\left(\mathrm{z}_{0}\right)=\mathrm{P}_{0}$ and non-stars earn zero profit. Of course, entry of stars that shifted demand up vertically by proportionally less than $\overline{\mathrm{z}}$ increased would have the same effects.

Entry of stars with average quality below $\bar{z}$ would cause a reduction in $P(\bar{z})$ initially, since demand would decrease along with the increase in supply. The result could then be the same as in the previous paragraph: non-stars would exit until $\mathrm{P}(\overline{\mathrm{z}})$ increased sufficiently so $\mathrm{P}\left(\mathrm{z}_{0}\right)=\mathrm{P}_{0}{ }^{18}$

If market demand were such that $\frac{\partial \ln \mathrm{P}^{\mathrm{D}}}{\partial \ln \overline{\mathrm{Z}}}>1$, then entry of stars that raised $\overline{\mathrm{z}}$ would shift demand more than proportionally to the increase in $\bar{z}$. In this case, consumers place a relatively high marginal value on increases in quality. If this increase in demand were large enough to just offset the fact supply is not vertical and also has increased, then $\mathrm{P}(\overline{\mathrm{z}})$ would have increased by exactly the same proportion by which $\bar{z}$ increased. Thus, the number of non-stars would not change as the number of stars increased: the

\footnotetext{
16 Equivalently, firms previously active and viewed as having $\mathrm{z}=\mathrm{z}_{0}$ could now be viewed as having $\mathrm{z}>\mathrm{z}_{0}$.

${ }^{17}$ Stars will earn positive profit in this model, so one with $\mathrm{z}>\mathrm{z}_{0}$ could charge a price slightly below $\mathrm{P}(\mathrm{z})=\frac{\mathrm{z}}{\mathrm{z}_{0}} \mathrm{P}_{0}$, still earn positive profit, and induce buyers to strictly prefer buying an item with $\mathrm{z}>\mathrm{z}_{0}$. Non-stars earn zero profit and can not lower price below $\mathrm{P}_{0}$.

${ }^{18}$ However, since $\overline{\mathrm{z}}$ has been reduced, it is possible the decrease in $\mathrm{P}(\overline{\mathrm{z}})$ would be small enough so $\mathrm{P}\left(\mathrm{z}_{0}\right)>\mathrm{P}_{0}$, in which case non-stars would earn positive profit, more of them would enter the market, demand would decrease due to the further reduction in $\bar{z}$, and both the supply increase and demand decrease would reduce $\mathrm{P}(\overline{\mathrm{z}})$ until $\mathrm{P}\left(\mathrm{z}_{0}\right)=\mathrm{P}_{0}$. Assume appropriate shapes for demand and supply, so the equilibrium does not result in a corner solution in which $\overline{\mathrm{Z}}$ is driven to $\mathrm{z}_{0}$ as supply increases and demand decreases continue to lead to $\mathrm{P}\left(\mathrm{z}_{0}\right)>\mathrm{P}_{0}$, and thus continued entry by non-stars.
} 
market would have immediately moved to the new long-run equilibrium point. Let the value of $\frac{\partial \ln \mathrm{P}^{\mathrm{D}}}{\partial \ln \overline{\mathrm{z}}}$ required for this to happen equal $\mathrm{x}$.

Now suppose $\frac{\partial \ln \mathrm{P}^{\mathrm{D}}}{\partial \ln \overline{\mathrm{z}}}>\mathrm{x}$. Entry of stars that increases $\overline{\mathrm{Z}}$ will increase demand enough so $\mathrm{P}(\overline{\mathrm{z}})$ will increase by more than the increase in $\bar{z}$. Now $P(\bar{z})>\frac{\bar{z}}{z_{0}} P_{0}$, and, with $P\left(z_{0}\right)=\frac{z_{0}}{\bar{z}} P(\bar{z})$, we have $\mathrm{P}\left(\mathrm{z}_{0}\right)>\mathrm{P}_{0}$ : non-stars earn positive profit, more of them will enter, market supply will increase, $\overline{\mathrm{z}}$ will decrease, and the latter effect will cause market demand to decrease. Both the decline in demand and the increase in supply will cause $\mathrm{P}(\overline{\mathrm{z}})$ to fall, and this process will continue until $\mathrm{P}\left(\mathrm{z}_{0}\right)=\mathrm{P}_{0}$.

\section{Superstar effects}

\section{A formal model}

A more formal analysis of a market with some stars is now developed. We use explicit functions for both firm cost and market demand. Specifically let a firm's total cost, C, be independent of z: $\mathrm{C}=\mathrm{q}^{2}+\mathrm{F}$, where $\mathrm{F}$ is again fixed cost. Entry and exit will force $\mathrm{P}\left(\mathrm{z}_{0}\right)$ equal to the height of the minimum point of average cost. At this point, $q=F^{1 / 2}$, and the height of average cost equals $2 \mathrm{~F}^{1 / 2} \equiv \mathrm{P}_{0}$. The inverse market demand is assumed to be: $\mathrm{P}^{\mathrm{D}}=\overline{\mathrm{z}}[\mathrm{A}-\mathrm{Q}]$, where $\mathrm{A}$ is a positive constant. Note, from Proposition Two, the demand function chosen implies $Q$ is independent of $\bar{z}$ in the long run.

In equilibrium $\mathrm{P}^{\mathrm{D}}=\mathrm{P}(\overline{\mathrm{z}})$, so, using eq.(12), and solving inverse market demand for $\mathrm{Q}$ :

$$
\mathrm{Q}=\mathrm{A}-\frac{\mathrm{P}(\overline{\mathrm{z}})}{\overline{\mathrm{Z}}}=\mathrm{A}-\frac{\mathrm{P}_{0}}{\mathrm{z}_{0}}
$$

From eq.(13), we have the long-run equilibrium point on market demand---where the market clears and arbitrage determines prices. Let $\mathrm{N}$ equal the number of non-stars in long-run equilibrium, and let $\mathrm{Q}_{\text {star }}$ equal the total quantity produced by stars, which depends on the distribution of stars. Each firm is a price taker, and profit is maximized when $\mathrm{P}(\mathrm{z})=2 \mathrm{q}$, so $\mathrm{q}=\mathrm{P}(\mathrm{z}) / 2$. In long-run equilibrium, $\mathrm{P}\left(\mathrm{z}_{0}\right)=\mathrm{P}_{0}$, and $\mathrm{P}(\mathrm{z})=\mathrm{P}_{0} \mathrm{z} / \mathrm{z}_{0}$. Each non-star produces $\mathrm{P}_{0} / 2$ units of output, and each star produces $\mathrm{P}_{0} \mathrm{z} / 2 \mathrm{z}_{0}$ units of output. Long run supply is: 


$$
\mathrm{Q}=\frac{\mathrm{P}_{0}}{2} \mathrm{~N}+\mathrm{Q}_{\text {star }}
$$

From eq.(14), we have the long-run equilibrium point on market supply, which, along with eq.(13), enables us to determine the number of non-stars, given $\mathrm{Q}_{\text {star. }}$ Setting eqs.(13) and (14) equal, we have:

$$
\mathrm{N}=\max \left(0,2\left[\frac{\mathrm{A}-\mathrm{Q}_{\text {Star }}}{\mathrm{P}_{0}}-\frac{1}{\mathrm{z}_{0}}\right]\right) .
$$

Assuming there are not enough stars to satisfy market demand, ${ }^{19}$ we have $\mathrm{N}>0$. Now suppose the distribution of stars is continuous, with a density of $\mathrm{h}(\mathrm{z})$ on the interval $\left(\mathrm{z}_{0}, \mathrm{z}_{\max }\right]$. With $\mathrm{q}(\mathrm{z})=\mathrm{zP}_{0} / 2 \mathrm{z}_{0}$ :

$$
\mathrm{Q}_{\mathrm{Star}}=\frac{\mathrm{P}_{0}}{2 \mathrm{z}_{0}} \int_{\mathrm{z}_{0}}^{\mathrm{z}_{\max }} \mathrm{zh}(\mathrm{z}) \mathrm{dz} .
$$

For additional insight, let $\mathrm{z}$ be distributed uniformly, with one star of each type, so $\mathrm{h}(\mathrm{z})=1$. Then:

$$
\mathrm{Q}_{\mathrm{star}}=\frac{\mathrm{P}_{0}}{4 \mathrm{z}_{0}}\left(\mathrm{z}_{\max }^{2}-\mathrm{z}_{0}^{2}\right)
$$

Using eqs.(15) and (17):

$$
\mathrm{N}=2\left[\frac{\mathrm{A}}{\mathrm{P}_{0}}-\frac{1}{\mathrm{z}_{0}}-\frac{1}{4 \mathrm{z}_{0}}\left(\mathrm{z}_{\max }^{2}-\mathrm{z}_{0}^{2}\right)\right] \text {. }
$$

From eq.(18), the number of non-stars, $\mathrm{N}$, is positively related to $\mathrm{A}$ and $\mathrm{z}_{0}$, and is negatively related to $\mathrm{P}_{0}$ and $\mathrm{z}_{\max }$. An increase in $\mathrm{A}$ implies an increase in market demand, so $\mathrm{N}$ increases. An increase in $\mathrm{z}_{0}$ implies a larger average quality in the market, and, given $\mathrm{z}_{\max }$, the existence of fewer stars, so a larger $\mathrm{N}$ results. A larger value for $\mathrm{P}_{0}$ implies a larger $\mathrm{q}$ for each firm, so fewer non-stars would operate. An increase in $\mathrm{z}_{\max }$ implies a larger average quality, but also means there are more stars; the latter effect dominates, so $\mathrm{N}$ decreases as $\mathrm{z}_{\max }$ rises. The negative effect of $\mathrm{z}_{\max }$ on $\mathrm{N}$ becomes larger (in absolute value) as $\mathrm{N}$ increases:

\footnotetext{
${ }^{19}$ This requires $\mathrm{Q}_{\text {star }}<\mathrm{A}-\frac{\mathrm{P}_{0}}{\mathrm{z}_{0}}$. The solution to eq.(15) when $\mathrm{N}>0$ requires rounding down to the nearest integer.
} 


$$
\frac{\partial \mathrm{N}}{\partial \mathbf{z}_{\max }}=-\frac{\mathrm{z}_{\max }}{\mathrm{z}_{0}}, \frac{\partial^{2} \mathrm{~N}}{\partial \mathrm{z}_{\max }^{2}}=-\frac{1}{\mathrm{z}_{0}}
$$

Consider the following example. Suppose $\mathrm{z}_{0}=1, \mathrm{P}_{0}=\$ 10$, and $\mathrm{A}=\$ 1000$. Then Table One illustrates how different values for $\mathrm{Z}_{\max }$ affect the number of non-stars $(\mathrm{N}){ }^{20}$

Table One.

\begin{tabular}{|c|c|}
\hline $\mathrm{Z}_{\max }$ & $\mathrm{N}$ \\
\hline 3 & 194 \\
\hline 5 & 186 \\
\hline 7 & 174 \\
\hline 9 & 138 \\
\hline 11 & 114 \\
\hline 13 & 86 \\
\hline
\end{tabular}

\section{Numerical examples of market equilibrium}

Krueger (2005) reports revenue for music concerts from 1982 to 2003. Most of the artists would fall under the heading of rock music, but other artists are included. ${ }^{21}$ In 1982 , the top $5 \%$ (in terms of revenue) of artists earned $62 \%$ of concert revenue. For 2003 , the corresponding figure was $84 \%$. To see if the competitive model developed herein can generate similar results, numerical examples are considered. As before, assume $\mathrm{z}_{0}=1, \mathrm{P}_{0}=\$ 10$, and $\mathrm{A}=\$ 1000$. Three examples are considered (Table Two) using eqs.(14) and (15). In all of these examples, stars are identical and combined represent approximately 5\% of the total number of producers. The 1982 concert results for the top 5\% of artists falls between the results found with 8 stars and $z_{\text {Star }}$ equal to either 5 or 6 . In the latter case, for example, $P_{\text {Star }}=\$ 60$, which

\footnotetext{
${ }^{20}$ Values for $\mathrm{Z}_{\max }$ were chosen to result in integer values for $\mathrm{N}$. Again, for $\mathrm{z}>\mathrm{z}_{0}, \mathrm{z}$ is distributed uniformally with a density of one.

${ }^{21}$ Among the non-rock artists are country performers (George Strait and Reba McEntire), a pop singer (Barbra Streisand), and an opera singer (Luciano Pavarotti).
} 
is 6 times the price for non-stars. From Figure 1 in Krueger (2005), it appears there was little disparity in ticket prices until the 1990s. Figure 2 in Krueger shows artists with the highest ticket prices had prices more than three times the $\$ 40$ plus average for recent years. In the theoretical model herein, using the second row of Table Two $\left(\mathrm{z}_{\text {star }}=6\right.$ and $\left.\mathrm{P}_{\text {star }}=\$ 60\right)$, the (weighted) average price for all sellers is approximately $\$ 22.12,{ }^{22}$ which implies a ratio of high-to-average prices of almost 3, and which suggests the results from the theoretical model herein may not be too different from the actual results for concerts.

The third example in Table Two---8 stars and $\mathrm{z}_{\text {Star }}=$ 9---yields almost exactly the result for the top 5\% earners for concerts in 2003: $84 \%$ of all revenue in both the theoretical model and for concerts, albeit for the top $6 \%$ of earners in the theoretical model. ${ }^{23}$ Again, these results do not involve imperfect substitution among sellers, nor is cost negatively related to product quality. Also, even with a star selling nine times as much as a non-star (when $\mathrm{z}_{\mathrm{Star}}=9$, $\mathrm{q}_{\text {Star }}=45$ vs. 5 for non-stars), each star sells less than $5 \%$ (45/990) of the total equilibrium quantity in this market: no seller has any appreciable market power. From row two to row three in Table Two, $\mathrm{z}_{\text {Star }}$ must rise by $50 \%$ in order to have a result similar to what actually occurred in the market for music concerts. The technological advances discussed in Section 1 (i.e. Walkman, Discman, and iPod) might explain an increase in $\mathrm{z}_{\text {star }}$ over the past two decades.

Table Two

\begin{tabular}{|c|c|c|c|c|c|c|c|}
\hline $\begin{array}{l}\text { \# of } \\
\text { stars }\end{array}$ & $\mathrm{z}_{\text {stars }}$ & $\mathrm{Q}_{\text {stars }}$ & $\mathrm{Q}_{\text {Non-stars }}$ & $\begin{array}{c}\text { \# of } \\
\text { Non-stars }\end{array}$ & $\begin{array}{c}\text { Stars' \% of total } \\
\text { \# of firms }\end{array}$ & Stars' \% of Q & Stars' \% of R \\
\hline 8 & 5 & 200 & 790 & 158 & $5 \%$ & $20 \%$ & $56 \%$ \\
\hline 8 & 6 & 240 & 750 & 150 & $5 \%$ & $24 \%$ & $66 \%$ \\
\hline 8 & 9 & 360 & 630 & 126 & $6 \%$ & $36 \%$ & $84 \%$ \\
\hline
\end{tabular}

Alternative assumptions about marginal cost and the quality level of stars

The numerical examples of the previous sub-section suggest a small percentage of firms may earn a large percentage of market revenue without imperfect substitution between sellers or marginal cost very

\footnotetext{
22 The average price is: $\$ 60\left(\frac{240}{990}\right)+\$ 10\left(\frac{750}{990}\right)$.

23 The average price in this case is approximately $\$ 39.09$, so $\mathrm{P}_{\text {Star }}$ is less than 2.5 times the average price.
} 
low and declining as quality increases. Now consider whether 1) the magnitude of marginal cost, and 2) the quality difference between stars and non-stars have a significant effect on the results herein. First, suppose cost is $C=2 q^{2}+25$, and there are eight identical stars with $z_{\text {star }}=5$. With the same market demand used above, $\mathrm{P}^{\mathrm{D}}=\overline{\mathrm{Z}}[1000-\mathrm{Q}]$, it is easy to find $\mathrm{N}=238,{ }^{24} \mathrm{P}_{0}=\$ 14.16, \mathrm{q}_{0}=3.54, \mathrm{P}_{\text {star }}=\$ 70.8$, $\mathrm{q}_{\text {star }}=17.7, \mathrm{Q}_{\text {non-star }}=842.52, \mathrm{Q}_{\text {star }}=141.6$, and $\mathrm{Q}=984.12$. In this case, the combined revenue of stars is $\$ 10,025$, and the combined revenue of non-stars is $\$ 11,930$. Stars represent $8 / 246$ firms, or $3.3 \%$ of all firms, and earn $46 \%$ of market revenue. Contrast this case to that in the top row of Table Two, where all parameters are the same, except the results in Table Two are derived with $\mathrm{C}=\mathrm{q}^{2}+25$. By doubling marginal cost, we have reduced stars share of market revenue from $56 \%$ to $46 \%$, but this lower share of market revenue goes to a smaller percentage of all firms---3.3\% vs. 4.8\%. Thus, a higher marginal cost will reduce the share of market revenue of a given set of stars, but the impact is not particularly large.

Now consider the effect of a relatively small quality difference between stars and non-stars. Again, use Table Two and the same cost and market demand assumed for that table. Suppose there are eight stars, each of which has $\mathrm{z}=2$. As before, $\mathrm{P}_{0}=\$ 10$, and $\mathrm{q}_{0}=5$. Now $\mathrm{P}_{\text {star }}=\$ 20, \mathrm{q}_{\text {star }}=10$, and $\mathrm{Q}_{\text {star }}=80$, so $\mathrm{Q}_{\text {non-star }}=910, \mathrm{~N}=182$, and stars represent $4.2 \%$ of all firms (8/190). Stars' combined revenue is $\$ 1600$, non-stars’ combined revenue is $\$ 9100$, and stars earn $15 \%$ of market revenue. Stars with double the quality of non-stars do earn a disproportionate share of market revenue, but their share is less than one third of what it would be if $\mathrm{z}_{\text {star }}=5$ (Table Two, top row). As suggested previously, a large quality difference between stars and non-stars is necessary for the existence of significant superstar effects.

\section{Ticket prices for rock concerts.}

\footnotetext{
${ }^{24} \mathrm{~N}$ is rounded down to the nearest integer.
} 
Krueger (2005) found the average concert ticket price increased almost five times as fast (82\% versus 17\%) as the CPI from 1996 to 2003 . Also, the top performers sold fewer tickets over this period. ${ }^{25}$ Krueger's explanation for these effects is based on a monopoly model. The introduction of zero-price music downloads during this period (i.e. Napster) suggests concerts and purchased CDs are not as strongly complementary as before; thus the absolute value of the (negative) cross-price elasticity of demand between concert ticket prices and purchased music CDs would have declined. This would induce a monopolist to charge a higher price for concerts, and to reduce the quantity of concert tickets sold.

A competitive model of rock music can explain the recent increase in concert prices. Suppose a seller produces both rock concerts and music CDs, and is a price taker in both markets. However, the price for concert tickets depends negatively on the price of a seller's recorded music consumers listen to, whether from CDs or internet downloads, if concerts and recorded music are complements. Let the amount of a seller's recorded music consumed equal $\mathrm{y}$, with the price of $\mathrm{y}$ equal to $\mathrm{P}_{\mathrm{y}}$. Then the price a seller of quality z can charge for a concert ticket is $\mathrm{P}\left(\mathrm{z}, \mathrm{P}_{\mathrm{y}}\right)$, and $\frac{\partial \mathrm{P}(\mathrm{z}, \mathrm{Y})}{\partial \mathrm{P}_{\mathrm{y}}}<0$. If a large percentage of recorded music consumed is now available at a zero price, the effective $\mathrm{P}_{\mathrm{y}}$ to buyers is reduced significantly. Oberholzer-Gee and Strumpf (2004) claim downloads have almost no effect on CD sales. However, Leibowitz (2003) argues there is a reduction in sales of CDs of one unit for every five to six downloads. If $\mathrm{P}_{\mathrm{y}}$ has effectively been reduced significantly, then $\mathrm{P}\left(\mathrm{z}, \mathrm{P}_{\mathrm{y}}\right)$ should have increased. Thus, either competition or monopoly could explain an increase in concert ticket prices. However, the competitive model does not predict a decline in output for stars. Thus, some monopoly power may be present in the market for music groups.

An alternative explanation for the decline in output (that is, fewer concerts performed) by stars ${ }^{26}$ involves the age of these performers, and is consistent with a competitive market. Artists with the highest revenue per show in 1996-'99 include the Eagles, Barbra Streisand, Jimmy Buffet, Eric Clapton, and Rod

\footnotetext{
${ }^{25}$ Krueger (2005) considered what happened to those who were the top revenue earners in the period 1996-'99. From the period 1994-'95 (before concert prices began to increase significantly [1997]) to the period 200-'01, the number of shows performed by these individuals or groups fell by $18 \%$, and revenue per show increased by $60 \%$.

${ }^{26}$ I thank David Dickinson for this argument.
} 
Stewart. All of these artists had reached middle age by the mid-1990s. It is possible age has increased their marginal cost of performing, resulting in a reduction in the profit-maximizing number of concerts per year.

\section{Summary}

A competitive model was developed herein in which there are many firms, a fraction of the potential producers with the lowest quality level are capable of satisfying market demand, and complete arbitrage occurs between prices of goods with different quality. The usual explanations for superstar effects---imperfect substitution between sellers, low marginal cost of output (implying the possibility of joint consumption), and, possibly, marginal cost declining as quality increases---were shown to be unnecessary for the existence of superstar effects. Indeed, with the simple cost function employed, a firm's revenue is positive and convex in quality when cost increases in quality at a decreasing rate. What is necessary in the model herein for a few firms to earn a disproportionately large share of market revenue is for these firms to have significantly higher quality than low quality firms, which is not necessary if different quality levels are poor substitutes or joint consumption occurs.

Frank and Cook (1992) refer to markets with superstar effects as “winner-take-all markets.” They suggest such effects result from indivisibilities---e.g. two tennis players can not work together to win a singles title---and rank-order contests in which payoffs do not depend on absolute quality. They conclude such markets have too many resources allocated to them due to rent-seeking by market participants. In the model herein, no rent-seeking occurs and the market is competitive. This suggests one should not conclude the equilibrium in all markets with superstar effects is inefficient.

Numerical examples using the model herein suggest its ability to replicate actual results in the market for music concerts, except possibly for the recent decline in output by top performers. In general, the results from the theoretical model suggest monopoly is not necessary for superstar effects to occur. A few producers, none of which sells a significant percentage of total output, can dominate a market in 
terms of their share of market revenue. Again, such a market simply requires these "stars" sell a product that is deemed to be of significantly higher quality than what is produced by most sellers. 


\section{Appendix}

In this appendix, consider whether revenue, given the profit-maximizing q, is necessarily convex in quality $(\mathrm{z})$ if total cost $(\mathrm{C})$ increases with $\mathrm{z}$ at a decreasing rate---the result found in the text for the case when $C=z^{\sigma} q^{\alpha}$, with $q=$ firm output and $\alpha>1$. Since it is the effect of $z$ on $C$ when $C$ is not an explicit function of $\mathrm{z}$ that is of interest, and the effect of $\mathrm{q}$ on $\mathrm{C}$ is not of interest, use the simplest specific functional relation between $\mathrm{q}$ and $\mathrm{C}$, with a general relation between $\mathrm{z}$ and $\mathrm{C}$ :

$$
\mathrm{C}=\mathrm{q}^{2} \mathrm{c}(\mathrm{z})
$$

where $\frac{\partial c}{\partial z} \equiv c_{z}>0$. Let $c_{z z} \equiv \frac{\partial^{2} c}{\partial z^{2}}$. With $\mathrm{R}=\mathrm{kzq}$ and $\mathrm{k}$ a positive constant, the first-order condition for the profit maximizing choice of $\mathrm{q}$ is:

$$
\mathrm{q}^{*}=\frac{\mathrm{kz}}{2 \mathrm{c}}
$$

Substituting into $\mathrm{R}$ using eq.(A2) yields $\mathrm{R}^{*}=\frac{\mathrm{k}^{2} \mathrm{z}^{2}}{2 \mathrm{c}}$. To get rid of constant terms, let $\mathrm{r} \equiv \frac{2}{\mathrm{k}^{2}} \mathrm{R}^{*}=\frac{\mathrm{z}^{2}}{\mathrm{c}}$, where the derivatives of $\mathrm{r}$ with respect to $\mathrm{z}$ are identical in sign to those of $\mathrm{R}^{*}$. Differentiating r:

$$
\frac{\partial r}{\partial z}=\frac{z}{c^{2}}\left(2 c-z c_{z}\right)
$$

In order for $\mathrm{R}^{*}$ to be positively related to $\mathrm{z}$, $\frac{\partial \mathrm{r}}{\partial \mathrm{z}}$ must be positive, so $2 \mathrm{c}>\mathrm{zc}_{\mathrm{z}}$, or, with $\xi_{\mathrm{c}, \mathrm{z}}$ the elasticity of $\mathrm{c}$ with respect to $\mathrm{z}, \xi_{\mathrm{c}, \mathrm{z}}<2$. Since the elasticity of $\mathrm{C}$ with respect to $\mathrm{q}$ is 2 , and the elasticities of $\mathrm{c}$ and $\mathrm{C}$ with respect to $\mathrm{z}$ are identical, the condition $\xi_{\mathrm{c}, \mathrm{z}}<2$ requires $\mathrm{z}$ to have a smaller impact on $\mathrm{C}$ than does q. Differentiating $\frac{\partial r}{\partial z}$ with respect to $\mathrm{z}$ :

$$
\frac{\partial^{2} r}{\partial z^{2}}=\frac{1}{c^{2}}\left[2 c-z^{2} c_{z z}-\frac{2 z c_{z}}{c}\left(2 c-z c_{z}\right)\right]
$$

The first term in brackets in eq.(A4) is positive, and, for $\frac{\partial r}{\partial z}>0$, the third term in brackets is negative. Thus, $\mathrm{c}$ increasing with $\mathrm{z}$ at a decreasing rate--- $\mathrm{C}_{\mathrm{zz}}<0$-----is neither necessary nor sufficient for revenue to increase at an increasing rate with $\mathrm{z}$, that is for $\frac{\partial^{2} r}{\partial z^{2}}>0$. 


\section{References}

Adler, Moshe. “Stardom and Talent.” American Economic Review 75 (March 1985): 208-212.

Becker, Gary S., and Murphy, Kevin M. Social Economics. Cambridge: Harvard University Press, 2000.

Borghans, Lex, and Groot, Loek. "Superstardom and Monopolistic Power: Why Media Stars Earn More Than Their Marginal Contributions to Welfare.” Journal of Institutional and Theoretical Economics 154 (September 1998): 546-571.

Frank, Robert H., and Cook, Philip J. “Winner-Take-All Markets.” Cornell University working paper, April 1992.

Hamlen, William A., Jr. “Superstardom in Popular Music: Empirical Evidence.” The Review of Economics and Statistics 73 (November 1991): 729-733.

Krueger, Alan B. “The Economics of Real Superstars: The Market for Rock Concerts in the Material World.” Journal of Labor Economic 23 (January 2005): 1-30.

Leibowitz, Stan. "Will MP3 downloads Annihilate the Record Industry?” University of Texas at Dallas working paper, June 2003.

MacDonald, Glenn M. “The Economics of Rising Stars.” American Economic Review 78 (March 1988): 155-166.

Oberholzer-Gee, Felix, and Strumpf, Koleman. "The Effect of File sharing on Record Sales: An Empirical Analysis.” University of North Carolina at Chapel Hill working paper, December 2004.

Rosen, Sherwin. "Hedonic Prices and Implicit Markets: Product Differentiation in Pure Competition.” Journal of Political Economy 82 (January-February 1974): 34-55.

. “The Economics of Superstars.” American Economic Review 71 (December 1981): 845-858.

. “The Economics of Superstars.” American Scholar 52 (Autumn 1983): 449-460.

Smith, Adam. The Wealth of Nations. Middlesex, UK: Penguin, 1976/1982.

Sorensen, Alan T. “Bestseller Lists and Product Variety: The Case of Book Sales.” Stanford University working paper, May 2004.

Varian, Hal R. Intermediate Microeconomics: A Modern Approach, $6^{\text {th }}$ ed. New York: W.W. Norton \& Company, 2003. 